Pacific Journal of Mathematics

RINGS OF ANALYTIC FUNCTIONS ON ANY SUBSET OF THE
COMPLEX PLANE 


\title{
RINGS ON ANALYTIC FUNCTIONS ON ANY SUBSET OF THE COMPLEX PLANE
}

\author{
LI PI Su
}

\begin{abstract}
We prove that for any two subsets $X, Y$ of $C$, the complex plane, $X$ and $Y$ are conformally homeomorphic if there is an isomorphism between $\mathfrak{H}(X)$ and $\mathfrak{X}(Y)$ which is the identity on constant functions.
\end{abstract}

It has been known for some time that the conformal structure of a domain in the complex plane or a Riemann surface is determined by the algebraic structure of certain rings of analytic functions on it. (See [3], [11], [12], [10], [9] and [8].) Iss'sa [5] shows this is also true for a Stein variety of positive dimension.

All functions considered here are complex single-valued.

Definition 1. Let $X$ be an arbitrary subset of $C$. A function $f$ on $X$ is said to be analytic at a point $p \in X$ if there is a power series $\sum_{n=0}^{\infty} \alpha_{n}(z-p)^{n}$ which converges for $|z-p|<R$, and $f(z)=$ $\sum_{n=0}^{\infty} \alpha_{n}(z-p)^{n}$ for all $z \in X$ and $|z-p|<R$, where $R>0$, and $\alpha_{n}$ is a complex number for each $n=0, \cdots$, and $f$ is said to be analytic on $X$ if it is analytic at each point of $X$.

Definition 2. Let $X$ and $Y$ be two arbitrary subspaces of $C$. A mapping $\tau$ from $X$ to $Y$ is said to be analytic mapping if $\tau$ is an analytic function on $X$ and has values in $Y . \tau$ is said to be a conformal mapping if $\tau$ is analytic, one-to-one, and onto. (See [2, Ch. II. §2].) For any two subsets $X, Y$ of $C, X, Y$ are said to be conformally homeomorphic if there is a one-to-one conformal mapping from $X$ onto $Y$.

Let $X$ be an arbitrary subset of $C$, and $\mathfrak{2}(X)=\{f: f$ is analytic on $X\}$. We can then easily show that $\mathfrak{A}(X)$ forms a ring with the constant function of value 1 as the identity $u$. By [1, p. 145], if $f \in \mathfrak{A}(X)$ and $Z(f)=\{x \in X: f(x)=0\}=\varnothing$, then $1 / f \in \mathfrak{A}(X)$.

Lemma 3. For $p \in X$, there is an $f \in M_{p}=\{f \in \mathfrak{U}(X): f(p)=0\}$ such that $Z(f)=\{p\}$ and $f$ belongs to no maximal ideal other than $M_{p}$.

Proof. Let $f(z)=z-p$. Then that $f \in M_{p}$ and $f$ belongs to no other fixed maximal ideal $[4,4.4]$ is clear. Now, suppose that $M$ is a free maximal ideal $[4,4.1]$ such that $f \in M$. Since $M$ is free, there is $g \in M$ such that $g(p) \neq 0$. Thus, we have $g(z)=\alpha+\sum_{j=0}^{\infty} \alpha_{k+j}(z-p)^{k+j}$ for $z \in X$ and $|z-p|<R$, for some $R>0, \alpha_{0} \neq 0, \alpha_{k} \neq 0$ and $k \geqq 1$. 
Hence $\alpha_{0}^{*}=g(z)-(z-p)^{k-1} \cdot f(z) \cdot h(z)$ for some $h \in \mathfrak{Y}(X)$. Now $f$, $g \in M$ which is an ideal, $\underline{\alpha_{0}} \in M$. This is impossible as $\alpha_{0} \neq 0$. Hence, the assertion holds.

LEMMA 4. If $\Phi$ is an isomorphism from $\mathfrak{A}(X)$ onto $\mathfrak{A}(Y)$, then $\Phi\left(M_{p}\right)$ is a fixed maximal ideal.

Proof. That $\Phi\left(M_{p}\right)$ is a maximal ideal is clear. From Lemma 3, there is an $f_{0} \in M_{p}$ such that $Z\left(f_{0}\right)=\{p\}$, and $f_{0}$ belongs to no other maximal ideal. Consider $Z\left(\Phi\left(f_{0}\right)\right)$. If $Z\left(\Phi\left(f_{0}\right)\right)=\varnothing$, then $\Phi\left(f_{0}\right)$ is a unit so that $\Phi\left(M_{p}\right)$ is the whole ring, $\mathfrak{X}(X)$. This is impossible. Hence, $Z\left(\Phi\left(f_{0}\right)\right) \neq \varnothing$. But if $Z\left(\Phi\left(f_{0}\right)\right)$ contains more than one point, say $q_{1}$ and $q_{2}$, then $\Phi\left(f_{0}\right) \in M_{q_{1}}$ and $M_{q_{2}}$ so that $f_{0}$ would belong to at least two maximal ideals which is again impossible. Hence $Z\left(\Phi\left(f_{0}\right)\right)=\{q\}$ for some $q \in Y$. Hence $\Phi\left(M_{p}\right)=M_{q}$ is fixed ideal.

TheOREM 5. Let $X$ and $Y$ be two subsets of $\boldsymbol{C}$, and $\Phi$ be an isomorphism from $\mathfrak{A}(Y)$ onto $\mathfrak{A}(X)$ such that it is the identity on the constant functions. Then $\Phi$ induces a mapping $\tau: X \rightarrow Y$, defined by $\Phi(g)=g \circ \tau$, and $\tau$ is a conformal mapping of $X$ onto $Y$.

Proof. Define $\tau$ to be a mapping from $X$ to $Y$ as follows: $\tau(p)=$ $\cap Z\left[\Phi^{-1}\left(M_{p}\right)\right]$. By hypothesis $\Phi^{-1}$ is an isomorphism of $\mathfrak{A}(X)$ onto $\mathfrak{A}(Y)$. By Lemma 4, $\Phi^{-1}\left(M_{p}\right)$ is a fixed maximal ideal in $\mathfrak{U}(Y)$. Thus, $\tau$ is a single-valued mapping. Evidently, $M_{\tau(p)}=\Phi^{-1}\left(M_{p}\right)$, and $\tau$ is oneto-one and onto. Now, for each $g \in \mathfrak{A}(Y)$, and $p \in X$, let $\Phi(g)(p)=\alpha$. Then $\Phi(g)-\alpha \in M_{p}, g-\Phi^{-1} \underline{(\alpha)} \in M_{\tau(p)}$, so that $g(\tau(p))=\Phi^{-1} \underline{(\alpha)}(\tau(p))=$ $\alpha=\Phi(g)(p)$. Hence $\Phi(g)=\bar{g} \circ \tau$. Similarly, $\Phi^{-1}(f)=f \circ \overline{\tau^{-1}}$, where $\tau^{-1} ; Y \rightarrow X$ with $\tau^{-1}(q)=\cap Z\left[\Phi\left(M_{q}\right)\right]$. If we choose $g(w)=w$ on $Y$, and $f(z)=z$ on $X$, then $\tau(p)=g \circ \tau(p)$, and $\tau^{-1}(q)=f \circ \tau^{-1}(q)$ are analytic. Hence, $\tau$ is a conformal mapping.

Corollary 6. Let $X$ and $Y$ be two subsets of $C$, and $\Phi$ be an isomorphism of $\mathfrak{A}(X)$ onto $\mathfrak{A}(Y)$ which is the identity on real constant functions. Then $X$ and $Y$ can be decomposed respectively into $X_{1} \cup X_{2}$ and $Y_{1} \cup Y_{2}$ such that the sets $X_{1}, X_{2}$ are open and disjoint in $X$ and similarly for $Y_{1}$ and $Y_{2}$, in such a way that $X_{1}$ is conformal with $Y_{1}$, and $X_{2}$ is anti-conformal with $Y_{2}$, where some of $X_{1}, X_{2}, Y_{1}$ and $Y_{2}$ could be empty.

Note that a set is anti-conformal with another set if it is conformal with its complex conjugate.

\footnotetext{
* $\alpha_{0}$ stands for the constant function of value $\alpha_{0}$.
} 
Proof. As in Theorem 5, the mapping $\tau$ defined by $\tau(p)=\cap Z\left[\Phi^{-1}\left(M_{p}\right)\right]$ is one-to-one and onto. We know that $\left(\Phi(\underline{i)})^{2}=\Phi(-\underline{1)}=-\underline{1}\right.$, hence $\Phi(i)=i,-i$ or $i$ on one clopen subset of $X$, say $X_{1}$, and $-i$ on $X_{2}=$ $\bar{X}-\overline{X_{1}}$, (which is then a clopen subset). We will set $X_{1}=X$ and $X_{2}=X$, respectively, according as $\Phi \underline{(i)}=i$ and $\Phi \underline{(i)}=-i$. Therefore, $\Phi(\alpha)=\underline{\alpha}$ on $X_{1}$, and $\bar{\alpha}$ on $X_{2}$ for any constant $\alpha$. Then, by an argument similar to that used in Theorem 5 , we can show that $\Phi(g)=g \circ \tau$ on $X_{1}$, and $\overline{g \circ \tau}$ on $X_{2}$; and $\Phi^{-1}(f)=f \circ \tau^{-1}$ on $X_{1}$ and $\overline{f \circ \tau^{-1}}$ on $X_{2}$, for any $g \in \mathfrak{R}(Y)$ and $f \in \mathfrak{A}(X)$. Hence the assertion holds.

REMARK. In Theorem 5, the condition that $\Phi$ is the identity on the constant functions can not be omitted. Consider $X=\{p\}, Y=\{q\}$. Then $\mathfrak{U}(X)=\boldsymbol{C}=\mathfrak{U}(Y)$. We know that there is an isomorphism of $C$ to $C$ other than $z \rightarrow z$ and $z \rightarrow \bar{z}$ (see [7, Remark on p. 119]). Define $\Phi: \mathfrak{A}(X) \rightarrow \mathfrak{U}(Y)$ in the obvious way. Then $\Phi(\alpha) \neq \alpha$ for some $\alpha \in \mathfrak{A}(Y)$. On the other hand, $\alpha \circ \tau(p)=\alpha$. Hence, $\Phi(\alpha) \neq \alpha \circ \tau$.

However, L. Bers shows that if $X$ and $Y$ are domains with boundary points, then every isomorphism of $\mathfrak{A}(Y)$ onto $\mathfrak{A}(X)$ induces a mapping which is either conformal or anti-conformal. (See [3].) Nevertheless, Royden [10], and Ozawa and Mizumoto [9] assumed that the given isomorphism preserves the constant functions. Recently, Nakai [8] ${ }^{* *}$ shows that if $X$ and $Y$ are open Riemann surfaces and $\Phi$ is such that $\Phi(i)=i$ (or $-i$ ), then $\Phi$ induces a conformal (or conjugate-conformal, resp.) mapping. Iss'sa [5]** shows that if $X$ and $Y$ are Stein varieties of positive dimensions, then $\Phi$ induces a unique conformal or a unique conjugate-conformal mapping.

THEOREM 7. Let $X$ and $Y$ be two subsets of $\boldsymbol{C}$, and $\tau$ be a conformal mapping of $X$ onto $Y$. Then the induced mapping $\tau^{\prime}$, defined by $\tau^{\prime}(g)=g \circ \tau$, is an isomorphism of $\mathfrak{A}(Y)$ onto $\mathfrak{A}(X)$ leaving the constant function unchanged.

Proof. Use the Weirstrass' double-series theorem in [6] to show the composition of $g \circ \tau \in \mathfrak{U}(X)$ for any $g \in \mathfrak{U}(Y)$. The others are obvious.

\section{REFERENCES}

1. L. V. Ahlfors, Complex Analysis, McGraw-Hill Book Company, Inc., New York, 1953.

2. L. V. Ahlfors and L. Sario, Riemann Surfaces, Princeton University Press, New Jersey, 1960.

3. L. Bers, On rings of analytic functions, Bull. Amer. Math. Soc., 54 (1948), 311-315.

4. L. Gillman and M. Jerison, Rings of Continuous Functions, D. Van Nostrand Company,

** The author wishes to express her thanks to the referee for bringing her attention to these two articles. 
Inc., New Jersey, 1960.

5. H. Iss'sa, On the meromorphic function field of a Stein variety, Ann. of Math., 83 (1966), 34-46.

6. K. Knopp, Theory of Functions, Dover Publications, Inc., New York, 1945.

7. J. P. Meyer, G. D. Mostor and J. H. Sampson, Fundamental Structures of Algebra, McGraw-Hill Book Company, Toronto, 1963.

8. M. Nakai, On rings of analytic functions on Riemann surfaces, Proc. Japan Acad., 39 (1963), 79-84.

9. M. Ozawa and H. Mizumoto, On rings of analytic functions, Japan J. Math., 29 (1959), 114-117.

10. H. L. Royden, Rings of analytic and meromorphic functions, Trans. Amer. Math. Soc., 83 (1956), 269-276.

11. W. Rudin, Some theorems on bounded analytic functions, Trans. Amer. Math. Soc., 78 (1955), 333-342.

12. - An algebraic characterization of conformal equivalence, Bull. Amer. Math. Soc., 61 (1955), 543.

Received April 14, 1971.

The UNIVERSity OF OKLAHOMA 


\section{PACIFIC JOURNAL OF MATHEMATICS}

\section{EDITORS}

\author{
H. SAMELSON \\ Stanford University \\ Stanford, California 94305 \\ C. R. HOBBY \\ University of Washington \\ Seattle, Washington 98105
}

\section{J. DuGundJI}

Department of Mathematics University of Southern California Los Angeles, California 90007

RICHARD ARENS

University of California

Los Angeles, California 90024

\section{ASSOCIATE EDITORS}
E. F. BECKENBACH
B. H. NeumanN
F. WOLF
K. YOSHIDA

\section{SUPPORTING INSTITUTIONS}

\author{
UNIVERSITY OF BRITISH COLUMBIA \\ CALIFORNIA INSTITUTE OF TECHNOLOGY \\ UNIVERSITY OF CALIFORNIA \\ MONTANA STATE UNIVERSITY \\ UNIVERSITY OF NEVADA \\ NEW MEXICO STATE UNIVERSITY \\ OREGON STATE UNIVERSITY \\ UNIVERSITY OF OREGON \\ OSAKA UNIVERSITY
}

\author{
UNIVERSITY OF SOUTHERN CALIFORNIA \\ STANFORD UNIVERSITY \\ UNIVERSITY OF TOKYO \\ UNIVERSITY OF UTAH \\ WASHINGTON STATE UNIVERSITY \\ UNIVERSITY OF WASHINGTON \\ AMERICAN MATHEMATICAL SOCIETY \\ NAVAL WEAPONS CENTER
}

The Supporting Institutions listed above contribute to the cost of publication of this Journal, but they are not owners or publishers and have no responsibility for its content or policies.

Mathematical papers intended for publication in the Pacific Journal of Mathematics should be in typed form or offset-reproduced, (not dittoed), double spaced with large margins. Underline Greek letters in red, German in green, and script in blue. The first paragraph or two must be capable of being used separately as a synopsis of the entire paper. The editorial "we" must not be used in the synopsis, and items of the bibliography should not be cited there unless absolutely necessary, in which case they must be identified by author and Journal, rather than by item number. Manuscripts, in duplicate if possible, may be sent to any one of the four editors. Please classify according to the scheme of Math. Rev. Index to Vol. 39. All other communications to the editors should be addressed to the managing editor, Richard Arens, University of California, Los Angeles, California, 90024.

50 reprints are provided free for each article; additional copies may be obtained at cost in multiples of 50 .

The Pacific Journal of Mathematics is published monthly. Effective with Volume 16 the price per volume (3 numbers) is $\$ 8.00$; single issues, $\$ 3.00$. Special price for current issues to individual faculty members of supporting institutions and to individual members of the American Mathematical Society: $\$ 4.00$ per volume; single issues $\$ 1.50$. Back numbers are available.

Subscriptions, orders for back numbers, and changes of address should be sent to Pacific Journal of Mathematics, 103 Highland Boulevard, Berkeley, California, 94708.

PUBLISHED BY PACIFIC JOURNAL OF MATHEMATICS, A NON-PROFIT CORPORATION

Printed at Kokusai Bunken Insatsusha (International Academic Printing Co., Ltd.), 270, 3-chome Totsuka-cho, Shinjuku-ku, Tokyo 160, Japan. 


\section{Pacific Journal of Mathematics}

\section{Vol. 42, No. $2 \quad$ February, 1972}

Stephen Richard Bernfeld, The extendability of solutions of perturbed scalar differential equations ................................. 277

James Edwin Brink, Inequalities involving $f_{-} p$ and $f^{(n)}{ }_{q}$ for $f$ with $n$

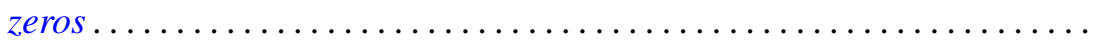

Orrin Frink and Robert S. Smith, On the distributivity of the lattice of filters of a groupoid

Donald Goldsmith, On the density of certain cohesive basic sequences .... 323

Charles Lemuel Hagopian, Planar images of decomposable continua . . . . . 329

W. N. Hudson, A decomposition theorem for biadditive processes ........ 333

W. N. Hudson, Continuity of sample functions of biadditive processes......

Masako Izumi and Shin-ichi Izumi, Integrability of trigonometric series.

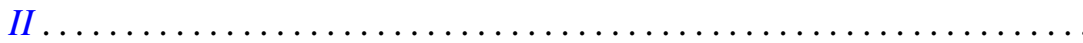

H. M. Ko, Fixed point theorems for point-to-set mappings and the set of

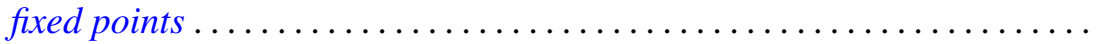

Gregers Louis Krabbe, An algebra of generalized functions on an open interval: two-sided operational calculus ...

Thomas Latimer Kriete, III, Complete non-selfadjointness of almost selfadjoint operators.................................

Shiva Narain Lal and Siya Ram, On the absolute Hausdorff summability of a Fourier series .

Ronald Leslie Lipsman, Representation theory of almost connected groups...

James R. McLaughlin, Integrated orthonormal series.... . .

H. Minc, On permanents of circulants.

Akihiro Okuyama, On a generalization of $\Sigma$-spaces.....

Norberto Salinas, Invariant subspaces and operators of class $(S)$

James D. Stafney, The spectrum of certain lower triangular matrices as operators on the $l_{p}$ spaces .......................

Arne Stray, Interpolation by analytic functions

$\mathrm{Li} \mathrm{Pi} \mathrm{Su}$, Rings of analytic functions on any subset of the complex plane.

R. J. Tondra, A property of manifolds compactly equivalent to compact manifolds.... 